\title{
Heritage Craft in Crisis: a Case Study of Flexible Brass Craft of Bellaguntha, Ganjam District of Odisha
}

\author{
Santosh Kumar Jha ${ }^{1}$
}

\begin{abstract}
For a researcher, studying the dynamics of a traditional handcraft and indigenous knowledge becomes interesting during the research identification process, especially when a study turns into a comparative one between what actually s/he has personally witnessed in its applied area and its pre-existing insufficiently documented database. Sometimes, these documents are supportive but just bear few insufficient bullet points with some of those being contraindicating too. On the other hand, the existing status of a craft includes indigenous craft techniques, hereditary knowledge, work culture, materials, tools, line of end products, socio-cultural importance of craft, associated folklore roots and other ingredients, which represents an overall set of 'evidenced legacy' of any traditional heritage. The present documented status of flexible brass craft of Bellaguntha is also suffering from above mentioned situation. This paper covers some of the interesting cases found by this author, during his studies of pre-existing documents, concerned with this craft and presents the dynamics of product designing. The purpose of the study is to conduct a systematic documentation to enrich the database about this craft for its manifold benefit.
\end{abstract}

Keywords: Traditional Crafts, Flexible brass craft of Bellaguntha, Kansari and Thathera community, Metal Crafts of India.

\section{Introduction}

Bellaguntha is a block headquarters located under the geographical territories of Ganjam district of Odisha, India. To identify the geographical location of Bellaguntha over a world map, an indicative flow map is illustrated in Figure-1 below (not to be scaled).

The flexible brass craft of Bellaguntha is an approximately 500-60o years old heritage craft of India. But there is no proper documentation available, which may provide a systematic understanding of this craft, not even for a beginner or enthusiast. Only a few sketchy descriptions about the craft are available in various documents. Further, some of the available documents are contra-indicatory and misleading (please refer, sections 4.3.1. and 4.3.2. below). Improper documentation is adversely affecting the sustenance of this traditional craft.

${ }^{1}$ Santosh Kumar Jha is working as a Senior Faculty and teaches Product and Accessories Design subjects to graduation and postgraduate students in the Footwear Design and Development Institute of Ministry of Commerce and Industries, Noida (India). Presently he is pursuing PhD degree program in Cultural Studies discipline of the Utkal University of Culture in Bhubaneswar with concentration in the area of Traditional Crafts and Product Design. ORCID: http://orcid.org/oooo-ooo1-5701-2107. Email: handicraftdesigner@gmail.com 


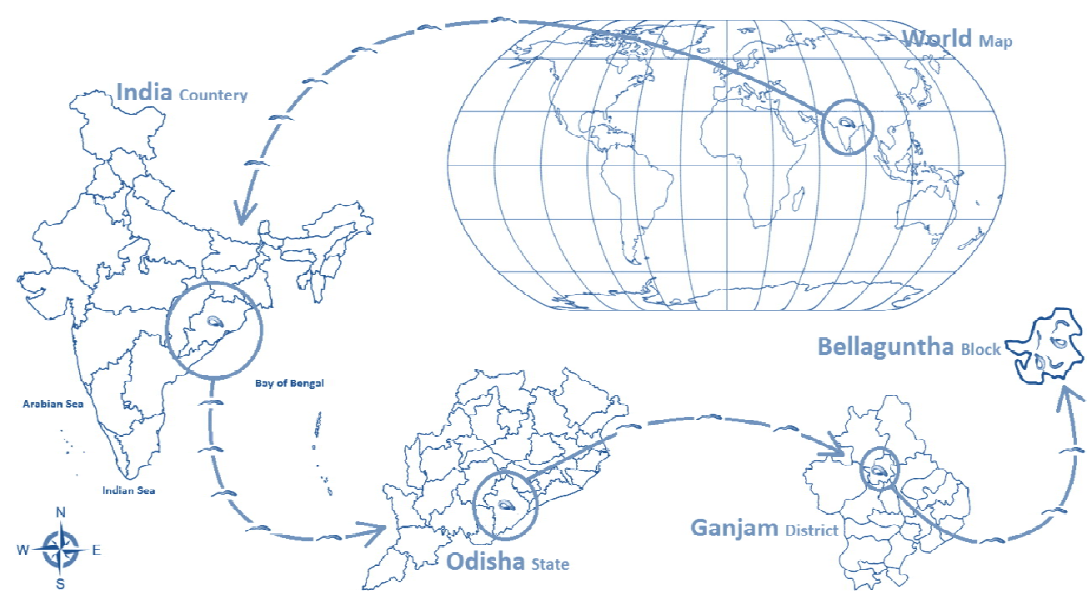

Figure-1: Location map of the Flexible brass craft cluster of Bellaguntha (composed by author)

\section{Purpose of Study}

A document is an evidence or proof, which may be compiled in written, printed, painted, drawn, sketched, sculpted, photographed and/or audio-visual recorded formats ${ }^{\mathrm{i}}$ etc. But, usually our craft artisans ignore to document ${ }^{\mathrm{ii}}$ their own activities with a systematic approach while being primarily engaged with the applied and operational segments of their crafts and to maintain their trade-secrets. Although, the artisan community itself is the primary and richest resource, they are expected to document their daily processes and experiences to conserve their knowledge database. So, the role of a researcher, who works in close consultation with these craft communities, goes higher to develop a database and form a systematic document to help such crafts bloom with systematic approach. The purpose of this study was to sum up different documents created through various modes and make a comparative study, which may help to create an updated document with authenticity.

\section{Methodology}

Literature survey data was collected from different sources, like, various reports, articles, research papers and websites. For this purpose, different secondary and tertiary data had been collected from various available sources and further verified at grassroots level, with consultation of concerned artisans. This phase of study was further classified into four broad sections.

\subsection{Literature Classification}

As the counting of primary literature was difficult to study and at the same time it was difficult to mark them for further use. So, the author found it important to classify them and divide them into three different broader sub-sections and place those pieces of printed papers into three different color markers. A color code identification system ${ }^{\mathrm{iii}}$ was followed and this researcher used red, green, blue colors ${ }^{\text {iv }}$ to categorize them: green marks indicating highly relevant set of literatures; blue marks indicating moderately relevant set of literatures, and read marks indicating contradictory set of literature. The colored classification helped this researcher to visually identify the category of information and classify them according to their sub-sections for inter-linking and creating logical flow of understanding. 


\subsubsection{Highly Relevant Literatures}

After a thorough study, these literature pieces were identified and marked with a green colored tick mark: " $\square$ " and entered in the primary section in the journal of green literature-cards. For this purpose, a $0.5 \mathrm{~mm}$ micro pencil with green lead was used to highlight required areas.

\subsubsection{Moderately Relevant Literatures}

These literature pieces were identified and marked with a blue colored tick mark: " $\boldsymbol{\nabla}$ " and entered in the secondary section in the journal of blue literature-cards. For this purpose, a $0.5 \mathrm{~mm}$ micro pencil with blue lead was used to highlight required areas.

\subsubsection{Contradictory Literatures}

These literature pieces were identified and marked with a red colored tick mark: " $\boldsymbol{Z}^{\prime}$ " and entered in the tertiary section in the journal of red literature-cards. For this purpose, a $0.5 \mathrm{~mm}$ micro pencil with red lead was used to highlight required areas.

\subsection{Preparation of Literature Understanding Notes}

In this phase the author studied and analyzed the information received from the respective literature, individually and tried to do all that carefully at his level best to understand and categorize the available raw data, extracted from available literature database.

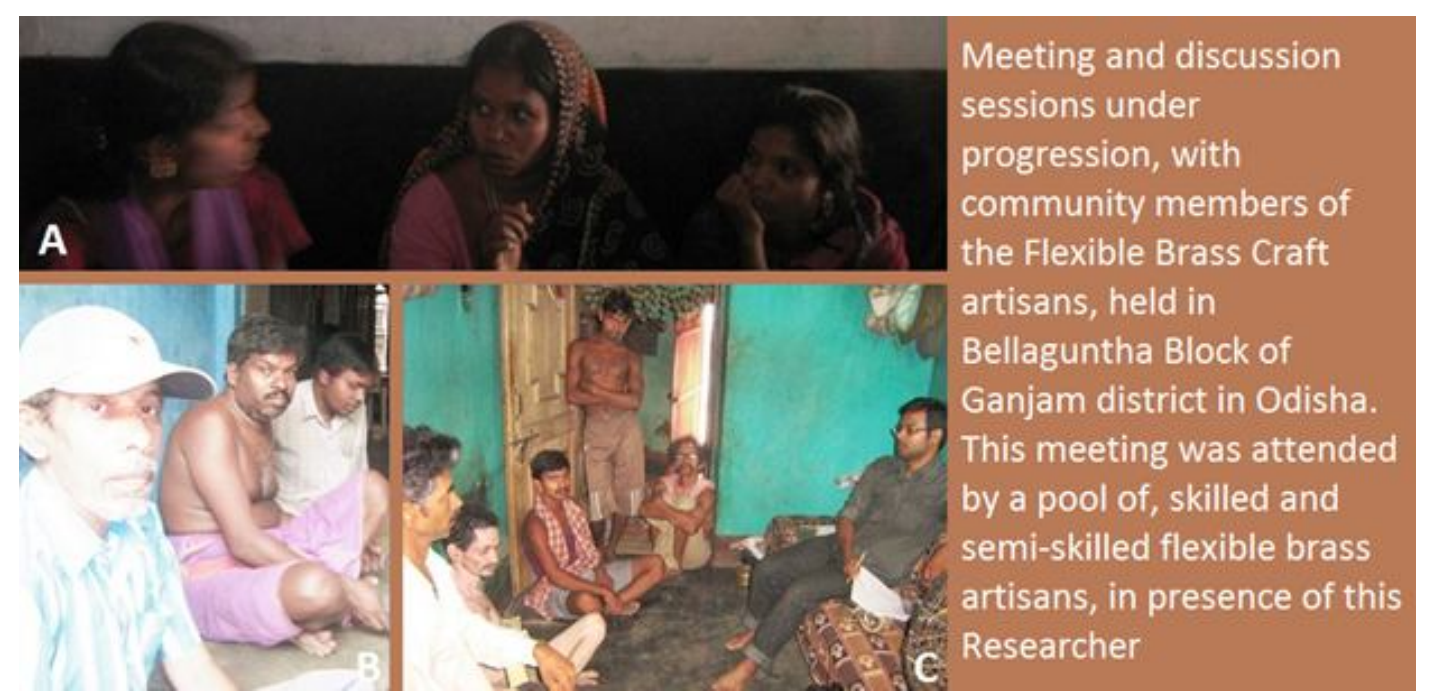

Figure-2: Community meeting with the flexible brass craft artisans in Bellaguntha

\subsection{Cross Verification of Collected Literature with Craftsperson}

After completion of literature collection phase, this researcher had approached the crafts persons of Bellaguntha and surrounding areas, who are involved in this craft today, and verified the correctness within the collected set of literature database and tried to reach at a common 
consent, to reduce error, through attending an open-house community meeting, which was followed by group discussions. Contradictory literatures were also discussed in this meeting. This common meeting was represented by a number of eleven skilled, which includes three ladies and eight male skilled and semi-skilled artisans.

\subsection{Preparation of Summary}

This part reflects the understanding, developed after completion of study phase, as discussed above.

\section{Literature Findings and Understandings}

4.1. Highly Relevant Documents (marked in green $\boldsymbol{\nabla}$ )

4.1.1. Geographic Location of Craft

\subsubsection{Finding(s):}

The following article carries information about the geographical identification of flexible brass craft in Bellaguntha area under Ganjam district of Orissa state in India. A document, titled: "Handicraft and Cottage Industries, Ganjam" was prepared by the Directorate of Handicraft and Cottage Industries, Government of Odisha. (Consulted on 04.12.2014) ${ }^{\mathrm{v}}$ :

"The manufacture of flexible brass fish of Bellaguntha area is a unique craft of the district."

Figure-3: Piece of Literature, documented by the Directorate of Handicraft and Cottage Industries, Odisha

\subsubsection{Understanding(s):}

This above piece of information, explains about:

4.1.1.2.1. Name of the craft is "Flexible Brass Fish".

4.1.1.2.2. The geographic location of this craft cluster is identified in the Bellaguntha block area of Ganjam district in Odisha state. Please refer, figure-4, below.

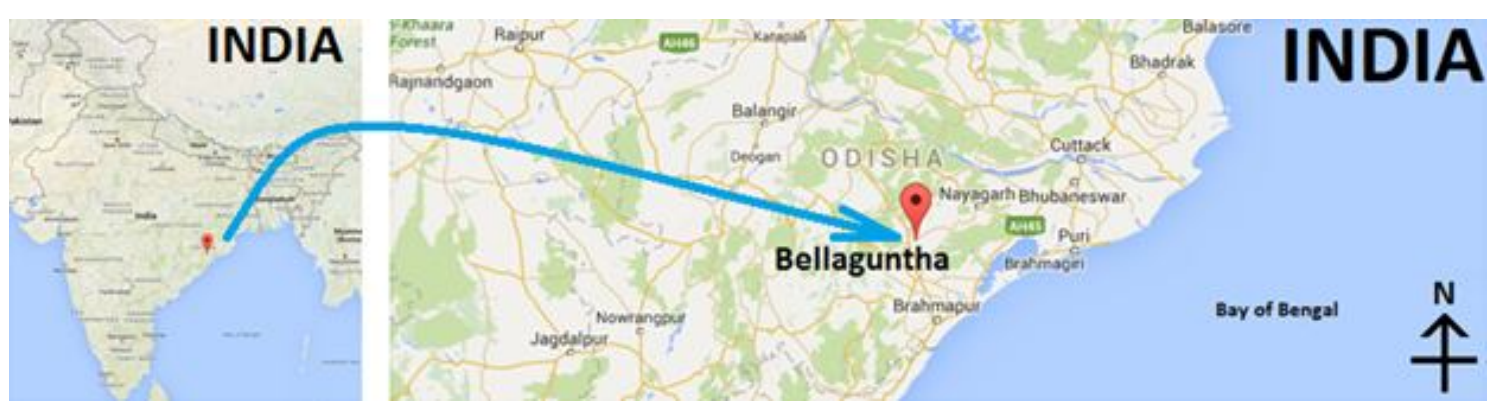

Figure-4: Geographical location of Bellaguntha on Google Maps (consulted on 29.06.2016)

4.1.1.2.3. Craft is under practice and craft products are being manufactured.

4.1.1.2.4. Brass is the primary raw material for this craft. 
4.1.1.2.5. Nature and qualities of this craft is able to reflect higher commercial potentials.

4.1.1.2.6. This is a 'unique' craft of this district. No other similar competitive threat there for this craft within the geographical boundaries of the Ganjam district.

4.1.1.2.7. The statement above also prevents this craft from a geographical identity threat ${ }^{\mathrm{vi}}$, projected by a contradictory document, which is discussed in section-4.3.2.

\subsubsection{Artisan Community Response(s):}

During a meeting with this researcher, artisan community members partially disagreed with the piece of information given in figure-3 and specifically covered under 4.1.1.2.1 above. This piece of literature reflects the name of the craft as "Flexible Brass Fish", which is not justified, as these artisans are also manufacturing other products like flexible brass snakes, lobster and some other forms, along with fishes. The artisan community had shown other than fish forms to this researcher, during his visits to their workshops.
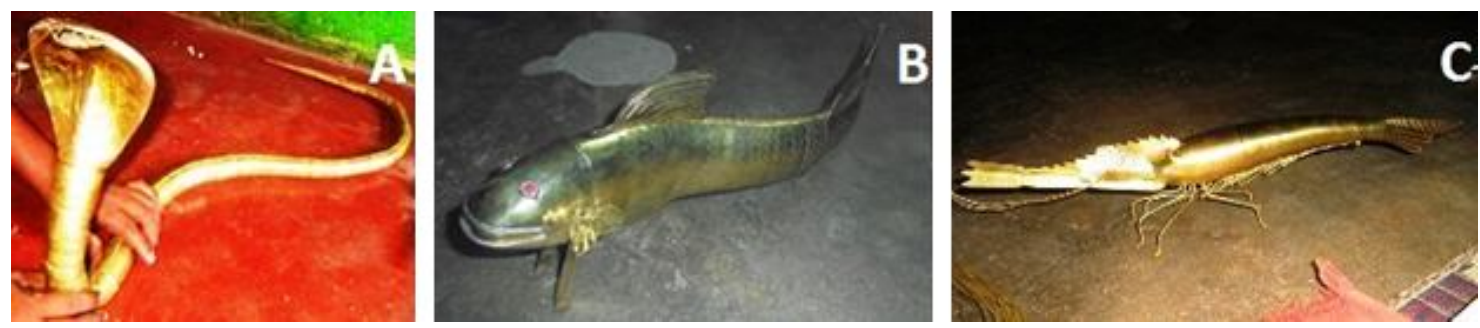

Figure-5: (A) Flexible brass snake, (B) Flexible brass fish, (C) Flexible brass lobster (photography by author)

\subsubsection{Craft Scenario}

\subsubsection{Finding(s):}

The following article explains that this is a unique craft with appealing design forms, like- brass fish etc. Under the broad area of materials, this craft comes under the category of "Bell Metal" family. This piece of literature is found in a document, titled: "Flexible Fish-Brass and Wood", which was prepared by the Council of Handicrafts Development Corporation, Office of Development Commissioner (Handicrafts), Ministry of Textiles, Government of India. (Consulted on 24.12.2014) vii:

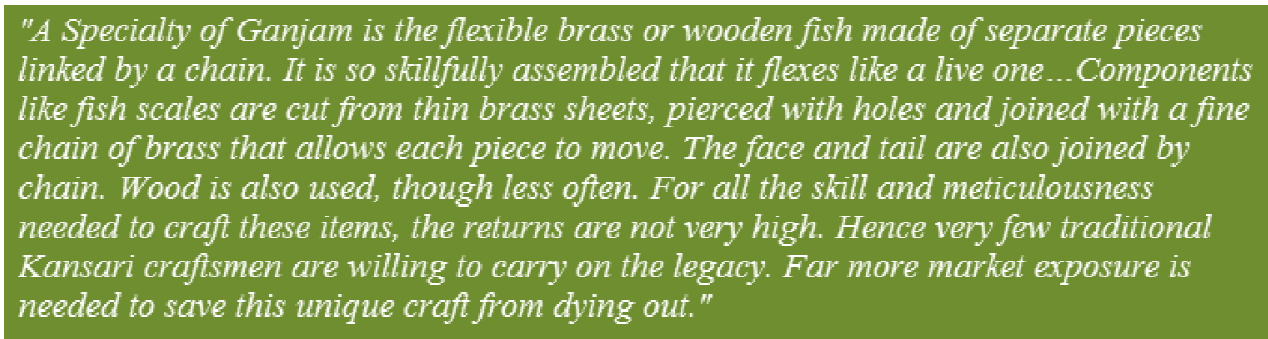

Figure-6: Piece of Literature, documented by the Council of Handicrafts Development Corporation

\subsubsection{Understanding(s):}

This above piece of information provides the following information: 
4.1.2.2.1. This craft belongs to Ganjam district of Odisha, India.

4.1.2.2.2. "Flexibility" is the unique feature of this craft, which is achieved through assembly of separate pieces through linking chains.

4.1.2.2.3. Craftsmanship requires a certain level of skill sets.

4.1.2.2.4. Manufacturing process is rigorous and involves cutting brass sheet, piercing with holes and joining through chain etc.

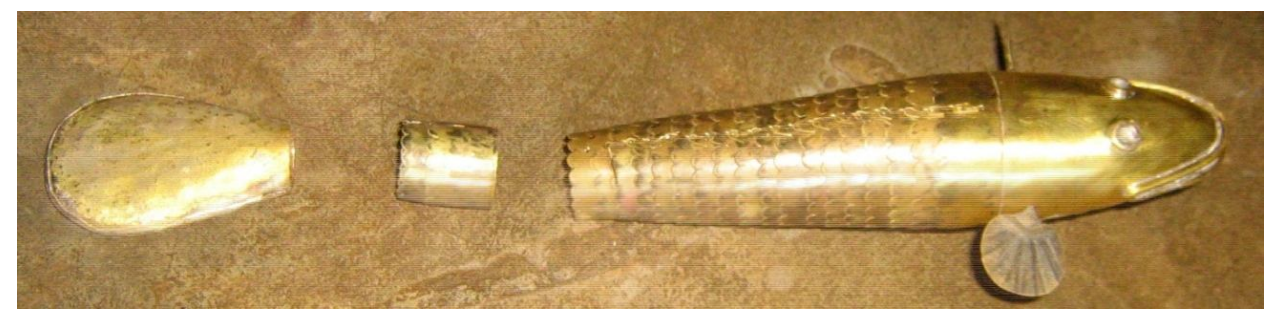

Figure-7: Parts of a brass flexible fish, under assembly process (photography by author)

4.1.2.2.5. Flexible fishes are available in two materials, i.e., brass and wood.

4.1.2.2.6. Craftsmanship is hard, but the reward in terms of money is not as per expectations.

4.1.2.2.7. Artisans are frustrated due to lack of profit, and so, very few of them are willing to carry their craft further.

4.1.2.2.8. This craft requires exposure to sustain further.

4.1.2.2.9. There is an immediate need to save this unique craft from dying out though different efforts.

4.1.2.2.10. This piece of information is also preventing this craft from the threats projected through few contradictory documents, which are discussed in sections-4.3.1. and 4.3.2.
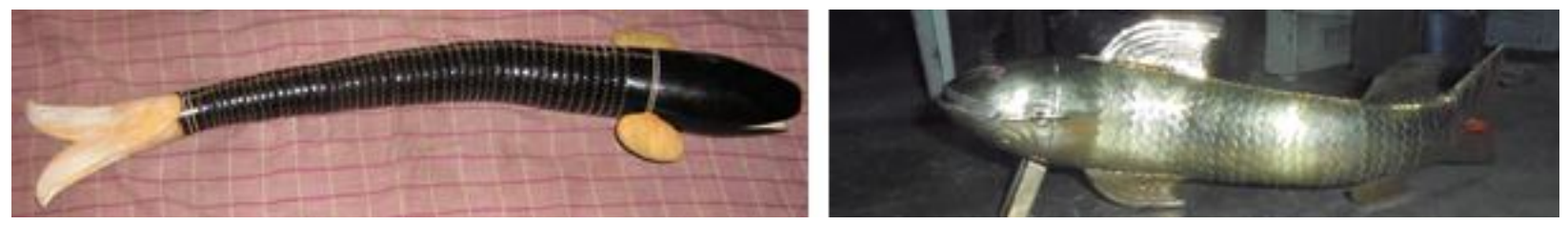

Figure-8: (A) A wooden replica of flexible fish, (B) Traditional flexible brass fish (photography by author)

\subsubsection{Artisan Community Response(s):}

During a meeting with this researcher, artisan community members partially disagreed with the piece of information given in figure- 8 and covered under 4.1.2.2.5. The community emphasized that only one craftsman is practicing this craft in Bellaguntha. Wooden forms are imitations and recent material diversification of their traditional flexible brass craft. Although, these wooden flexible products are visually close-similar to their traditional flexible brass products, but by their original hereditary craft principles and also by other technical parameters, both are completely different, as the raw materials are of different nature. Crafting with these wooden forms require wood cutting, planning, turning, colored lacquer applications, which is not at all relevant for flexible brass products etc. In the same line of argument, next phase of discussion was focused over quantity of production, as well as, the total number of artisans involved in flexible brass 
products is quite higher then wood. So, this is irrelevant to give equal weightage to wooden products in comparison to flexible brass products, in document's title.

\subsubsection{Artisan Scenario}

\subsubsection{Finding(s):}

A piece of literature, titled: "Brass and Bell Metal Works", was prepared under "Parampara Project", initiated by the Ministry of Culture of Government of India. It relates the existing condition of flexible brass craft and emphasizes the needs for product design diversification and invites interventions at different levels like- materials, cognitive consumer psychology, manufacturing processes and technology etc. (Consulted on 18.12.2014) ${ }^{\text {viii. }}$ :

\section{...In couple of decades, this traditional craft activity has received a great \\ set-back, because of shift of demand for steel, aluminium and plastic \\ products. For sustainable development of this craft, product diversification with introduction of appropriate technology is inevitable. "}

Figure-9: Piece of Literature, documented by the Ministry of Culture, Government of India

\subsubsection{Understanding(s):}

4.1.3.2.1. This craft is under practice, since last couple of decades.

4.1.3.2.2. Flexible brass craft is a traditional craft.

4.1.3.2.3. This craft had witnessed its glorified professional era and was in higher consumer demands for centuries.

4.1.3.2.4. Rising material based consumer demands for steel, aluminum and plastic like other materials is responsible for set-back of craft's professional growth.

4.1.3.2.5. The craft is under the threat of sustenance.

4.1.3.2.6. The craft requires product diversification.

4.1.3.2.7. Use of appropriate technology in manufacturing process is required.

\subsubsection{Artisan Community Response(s):}

During a meeting with this researcher, artisan community members partially disagreed with the piece of statement given in figure-9 and specifically covered under 4.1.3.2.4. They opined that using steel and plastic as basic raw materials, by replacing brass, is technically not feasible to develop products through existing craft traditions and so requires sufficient technical interventions in terms of tools, machineries, craftsmanship approaches. And even if they agree to accept such changes, what about the identity and long achieved legacy of this craft? As, the solution of above raised issue, given in figure- 9 above, they projected the needs of speeding up existing production process, where the role of upgradation in manufacturing technology and process will play important role, by adding advanced tools and machines, which can support and go along with their existing manufacturing process, without much additional efforts and most importantly, it should help to reduce the overall production cost. 


\subsubsection{Customer Recognition}

\subsubsection{Finding(s):}

The flexible craft has a little, but global appearance and recognition. So, Craft life-cycle can be reestablished, if the product ranges and required other interrelated issues get solved as per the need and demand of market. Dr. Prafulla Chandra Mohanty writes in his journal article, titled: "Handicrafts: The Visible Cultural Symbol of Ganjam District" ix , published in the Orissa Review, in its January' 2010 edition:

\section{"Flexible brass fish produced in Bellaguntha in the Ganjam District has attracted} customers all over the world."

Figure-1o: Piece of Literature, documented by Dr. Prafulla Chandra Mohanty, Orissa Review, January'zo1o

\subsubsection{Understanding(s):}

4.1.4.2.1. Flexible brass fish is a physical product ${ }^{\mathrm{x}}$.

4.1.4.2.1. These flexible brass products have attracted customers from different parts of the world.

\subsubsection{Artisan Community Response(s):}

Artisan community supported the statement, displayed in figure-10 above, with their common voice and considered this piece of information as a positive sign, towards customer-acceptance potentials in present time.

\subsubsection{Required Research Method}

\subsubsection{Finding(s):}

A piece of information published by the Small Industries Service Institute of Cuttack, in its document, titled: "Diagnostic study report of brass and bell metal cluster at Balakanti, Khurda" reads as given in figure-11 below. (Consulted on 11.01.2015) ${ }^{\mathrm{xi}}$ :

\section{"The data and information has been got by interviewing the individual artisans/SSI units, raw material suppliers, office bearers of cooperative societies, local banks and other stake holders and also secondary information has been collected from different offices."}

Figure-11: Piece of Literature, documented by the Small Industries Service Institute, Cuttack

\subsubsection{Understanding(s):}

4.1.5.2.1. Study at grassroots-level is required on priority basis.

4.1.5.2.1. The data and information have to be collected by interviewing individual artisans, raw material suppliers, office bearers of craft oriented self-help groups ${ }^{\mathrm{xii}}$, local banks and other stake holders and the secondary set of information may also be collected from different offices and 
organizations of central and state governments. This methodology has already been tested and the project work is published by some other researcher in a much closer area, which can be followed with required alterations, by considering actual scenario at grass root level, so that the desired level of precision and correctness in grass root data, can be achieved and cultivated further.

\subsection{Moderately Relevant Documents (marked in blue $\mathbf{b}$ )}

As these documents were repetitive in nature, and discussed set of information already covered under 4.1.1 to 4.1.5 and so they have been omitted by the researcher to minimize the repetition of fact.

\subsection{Contradictory Documents (marked in red $\boldsymbol{\nabla}$ )}

4.3.1. Flexible brass craft of Bellaguntha, is NOT a Dhokra Craft ${ }^{\text {xiii,xiv }}$

\subsubsection{Finding(s):}

A document, titled: "Dhokra", published by the "Craftmark: Hand Made in India", a leading organization with wider impact in Indian crafts sectors, writes about flexible brass craft of Bellaguntha on their document's page number-04, under the subtitle of "Producer Communities", (Consulted on 18.12.2014) ${ }^{\mathrm{xv}}$ :

\section{"... One type of dhokra handicraft that can be described as residual consists mainly of unique flexible brass items like the brass fish and snakes made by the craftsmen of Belguntha in the Ganjam district."}

Figure-12: Original text: Literature, documented by the "Craftmark: Hand Made in India"

\subsubsection{Artisan Community Response(s):}

During the common meeting with artisan community, called for cross verification of collected literature database (please refer 3.3. above), the artisan community refused to agree unanimously with the statement shown in figures-12, to the statement that the flexible brass craft can be described or categorized as a type of "Dhokra" craft.

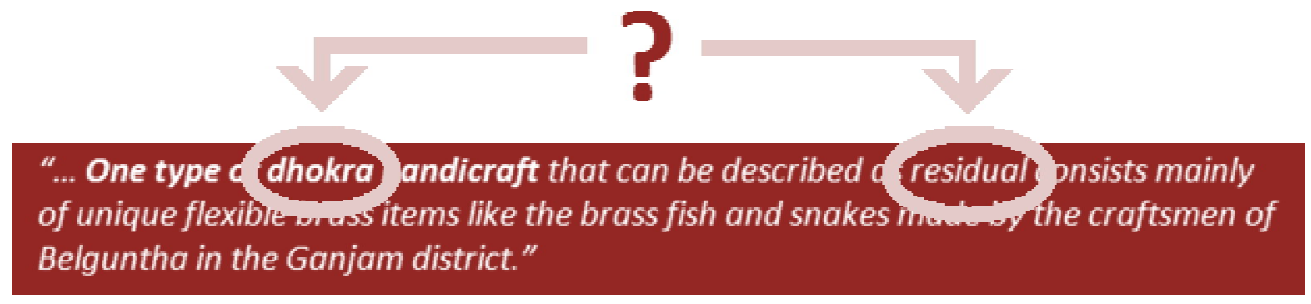

Figure-13

Further, in the common opinion of the community, their entire technique has no relevance with Dhokra, as Dhokra is a traditional lost wax casting process ${ }^{\mathrm{xvi}}$ based brass casting craft. A set of photograph collected from different flexible brass craft workshops in Bellaguntha is demonstration different phases of a fresh brass-sheet treatment involved with this craft, in figure- 
14, below. So, there was no any direct or indirect relevance of flexible brass craft of Bellaguntha with Dhokra craft, had been found, during craft process study.

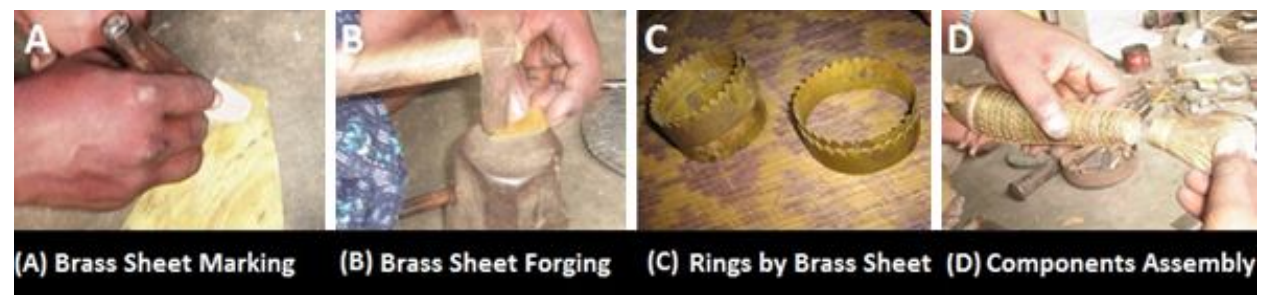

Figure-14: few stages of flexible brass craft manufacturing process (Photography by author)

The artisans of flexible brass craft also refused to accept that their craft's categorization as a residual craft, because in terms of raw materials used in flexible brass craft. Artisans informed this researcher that they are using fresh and high quality brass sheets of different thicknesses and copper wire like raw materials, so, their craft cannot be categorize as a residual craft (please refer figure-14, above). The artisan community also informed that they are not belonging to any scheduled tribe and that traditionally they are descendants of professional makers of war-weapon and accessories for the past kings of the region. They rather belong to the brass-smith community, which is locally also called as Kansari. So, calling this flexible brass craft Dhokra is inappropriate.
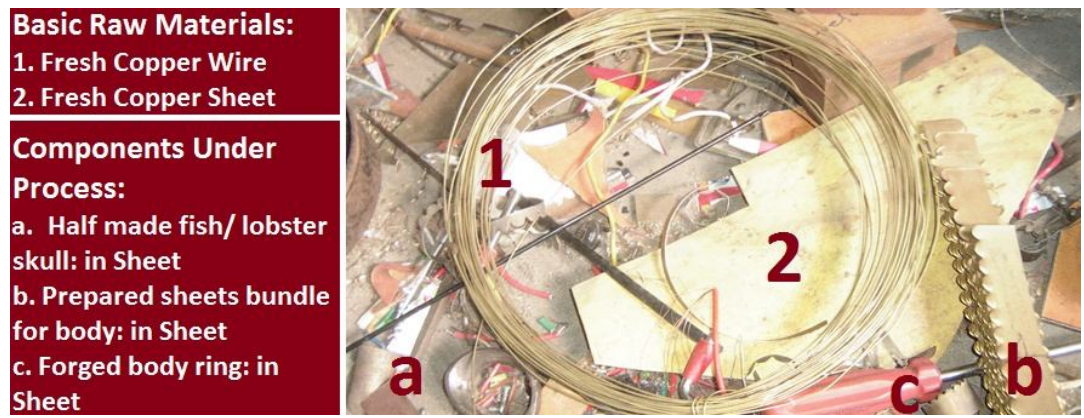

Figure-15: Basic raw materials of flexible brass craft and few components (Photography by author)

Even, some of these artisans, within community, who are involved in brass casting practices, are using residual brass scraps, produced as wastages, after flexible brass crafting process, to cast and develop other brass products and utensils through sand-casting methods (please refer image-16, below), which are not at all related to the traditional lost wax process, as reported in the document shown in figure-12 above.
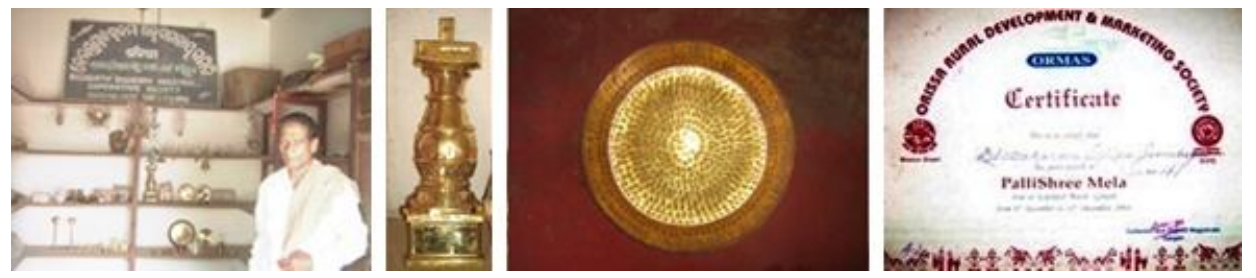

Image-16: Few sand-cast products of Bellaguntha with an exhibition certificate (Photography by author)

\subsubsection{Flexible brass craft is NOT a Craft of Andhara Pradesh}

\subsubsection{Finding(s):}

The Crafts Council of India, is a part of the World Crafts Council and is well-known for its contributions in the crafts sector worldwide. Its webpage, titled: "Flexible Fish Brass \& Wood" 
shows the flexible brass craft as a craft of Andhra Pradesh by displaying Bellaguntha artisans' works in brass and wood, without any other textual description in its open and public accessible page. (Consulted on 18.12.2014) ${ }^{\text {xvii }}$ :

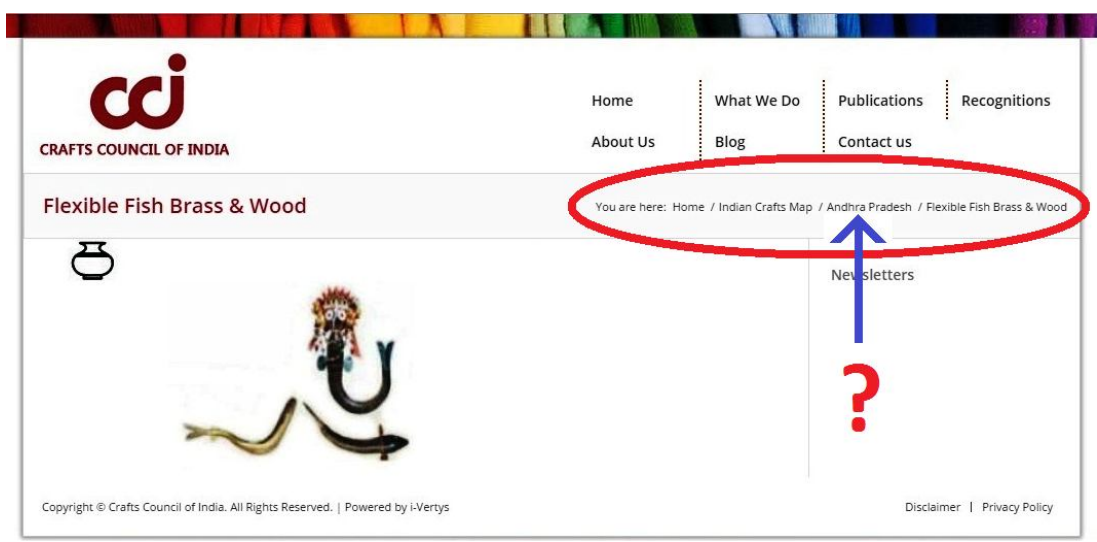

Figure-17: A screen shot of Visual Literature, documented and published by the Crafts Council of India, on its official webpage, informing about "Flexible Fish Brass \& Wood", is a craft of Andhra Pradesh, by showing same flexible brass fish forms, which are crafted by the artisans of Bellaguntha in Odisha state

\subsubsection{Artisan Community Response(s):}

During the meeting with artisan community, for cross verification of collected literature database (please refer 3.3. above), artisan community of Bellaguntha strongly refused to agree with the statement shown in figure-17, above, with a common voice. According to them, this document is projecting a geographical identity threat to the flexible brass craft of Bellaguntha. A set of documents was made available to the researcher by artisan community, in support of their geographical identity and belongingness with Bellaguntha area of Ganjam district in Odisha state. Please refer image-18, below.
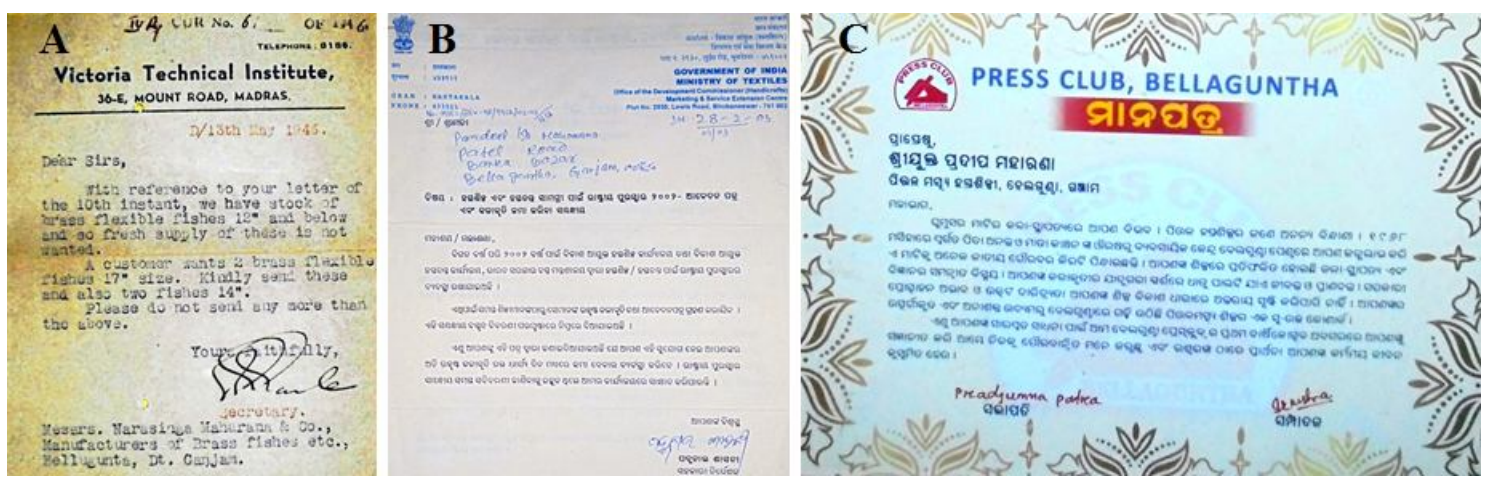

Image-18: A letter from Victoria Technical Institute, British Government, dated: 13.05.1946 (B) A letter from Ministry of Textiles, Gov. of India, dated: 28.02.2003 (C) An appreciation certificate (Photography by author)

\subsubsection{Researcher's Comment(s):}

4.3.2.3.1. Same visual images, as figure-17, are available in another document, developed by the Council of Handicrafts Development Corporations of Ministry of Textiles, Government of India, titled: "Flexible Fish-Brass and Wood". xviii The Council of Handicrafts Development Corporation's document displays correct geographical identity and establishing this craft's geographical identity 
with Bellaguntha area, which is situated under the boundaries of the Ganjam district in Odisha state of India.

4.3.2.3.2. A journal paper, which was authored by Dr. Prafulla Chandra Mohanty, published in the Orissa Review in January 2010 with title: "Handicrafts: The Visible Cultural Symbol of Ganjam District," "xix writes on its page number 42 that this craft belongs to Bellaguntha area of Ganjam district in Odisha state.

So, both of these documents can be treated as more authentic sources of information as the first document discussed in 4.3.2.3.1., is developed by an agency of Government of India, while the second document, discussed in 4.3.2.3.2., is a peer reviewed journal, which is published by an agency of the State Government of Odisha. Both these documents, along with o3 supportive documents- received from artisans clearly establish the relevance of flexible brass craft with Bellaguntha.

\section{Limitations of Existing Literature Resources}

As per this researcher's literature survey there was no detailed book or systematically published monograph or report available on the flexible brass craft of Bellaguntha- both online and offline. Few literature pieces were found on the craft of Bellaguntha, available with limited set of information during my offline and online literature search, and they were of indicative nature sometimes, not more than few sentences or sometimes merely as bullet points- of which most of them were only focusing over other larger segment and were unable to represent respective large scenario coverage of this craft.

\section{Limitations of Existing Literature Resources}

Even, most of the available literature, (as discussed under 4.1.1, 4.1.2, 4.1.4) contained the information that there is a craft in Bellaguntha, named- "Flexible Brass Fish Craft". This researcher found that available set of literature on flexible brass craft was not sufficient to justify the craft name even and most of the documents was projecting the partially justified craft name as "Flexible Brass Fish Craft", where presence of the term: "Fish", in craft's name is only able to justify a single form of product, i.e., flexible brass fish form. But, during field visits, to Bellaguntha, this researcher came to know that there is several other product forms available there, which are under regular craftsmanship, and developed by artisans through following similar production techniques. Some of them are- flexible brass lobster forms, flexible brass snake forms, and flexible brass tortoises form etc. So, this partial justified name is limiting new design diversification activities within the craft community and also limiting a remote consumer focused demand and supply chain. Both of them are imposing negative impacts over the craft.

So, during the artisan community meeting (please refer section-3.3), in presence of this

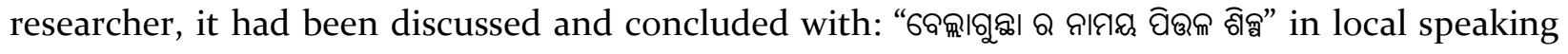
Odiya language or "Flexible Brass Craft of Bellaguntha" in English language. This name is able to represent entire set of products, produced by the flexible brass craft community in Bellaguntha, without any product specific bias. Following table-1, displays the meaning of each individual word carried under craft's name: 


\begin{tabular}{|c|}
\hline Odiya Name \\
\hline જાЯぬ \\
\hline ฮิฉก \\
\hline ธิศี \\
\hline Q \\
\hline 6৫শ।|ฌ| \\
\hline
\end{tabular}

\section{Conclusion}

Existing literary ambiguities may affect further intellectual research and adversely lead to limit the horizons of growth for flexible brass craft. So, this is important to conduct a systematic and comprehensive documentation, which will explain and establish the craft identity. The documentation process for a traditional craft should be explored in all required ways. The role of honestly prepared and well tested authentic documentation goes higher over a research priority index ${ }^{\mathrm{xx}}$.

This is important to protect a cultural heritage craft for our forthcoming generations. Which will help the target users to bring the same legacy into their life and lifestyles, as our present generation is enjoying and our ancestors had enjoyed for centuries. So, the role of qualitative documentation is not only important to protect this traditional craft of Bellaguntha, which is today dying out due to ignorance, but also about protection of traditionally earned, knowledge based intellectual growth. Further, such documents will also be helpful in the study of existing craft, craft scenario, professional status of the artisans, their livelihood and present consumer's psycho-sociological behaviors toward the acceptance of heritage crafts and other indigenous knowledge ${ }^{x x i}$, and help our next generation of researchers to receive refined research nodes from our present generation of researchers. This will enhance the accuracy in further research processes with futuristic approach in different areas of traditional knowledge ${ }^{\text {xxii }}$ likecraft studies, product design, cultural studies, history of art, social works, consumer psychology, sculpture, visual arts and other similar interdisciplinary areas of research and helpful for enriching, qualitative research databases.

\section{Acknowledgement}

This paper is an outcome of an ongoing PhD research work, registered under the Utkal University of Culture in Bhubaneswar and carried out by this researcher, under supervision of Dr. Alekha Charan Sahoo and facilitated by the master craftsman of flexible brass craft, Sri Pradeep Kumar Maharana and supported by other flexible brass community members in Bellaguntha block of Ganjam district in Odisha (India).

\section{Bibliography}

Bhattacharya, S. (2011). Dhokra Art and Artists of Bikna: Problems and Prospects. Chitrolekha International Magazine on Art and Design, Vol. 1, No. 2 , 10-13.

Blutner. (2015). Color Basics. Retrieved December 14, 2015, from http://www.blutner.de/color/colour.pdf 
Chatterjee, S. (2015). The Ancient Craft of Dhokra: A case study at Bikna and Dariapur in West Bengal. International Research Journal of Interdisciplinary \& Multidisciplinary Studies (IRJIMS), Volume-I, Issue$I V, 19-23$.

Council of Handicrafts Development Corporation. (2014). Flexible Fish-Brass E Wood. Retrieved December 24, 2014, from http://www.cohands.in/handmadepages/pdf.204/pdf

Council of Handicrafts Development Corporations, Ministry of Textiles, Government of India. (n.d.). FLEXIBLE FISH-BRASS AND WOOD. Retrieved June 27, 2016, from http://www.cohands.in/handmadepages/pdf/204.pdf

Council of Handicrafts Development Corporations, Ministry of Textiles, Government of India. (n.d.). Ganjam. Retrieved June 27, 2016, from http://www.cohands.in/handmadepages/pdf/202.pdf

Craft and Artisans. (2010). Dhokra Metal Casting of Orissa. Retrieved June 27, 2016, from http://www.craftandartisans.com/dhokra-metal-casting-of-orissa.html

Craftmark. (2016). About Us: About Craftmark. Retrieved June 27, 2016, from http://www.craftmark.org/about-us

Craftmark: Hand Made in India. (2014). DHOKRA. Retrieved December 18, 2014, from http://www.craftmark.org/sites/default/files/Po17\%2oDhokra.pdf

Crafts Council of India. (2014). Flexible Fish Brass \& Wood. Retrieved December 18, 2014, from You are here:Home / Indian Crafts Map / Andhra Pradesh / Flexible Fish Brass \& Wood:

http://www.craftscouncilofindia.org/craft-process/flexible-fish-brass-wood/

dictionary.com. (2016). document. Retrieved May 21, 2016, from http://www.dictionary.com/browse/document

Directorate of Handicraft and Cottage Industries, Government of Odisha. (2015). Handicraft E Cottage Industries, Ganjam. Retrieved December 04, 2104, from http://ganjam.nic.in/industry/handi_cottage_industries.htm

foxycart! (2016). Real, Tangible Products. Retrieved June 24, 2016, from Features: http://www.foxycart.com/features/feature/products/physical-products

Halvorsen, T. (2011, January 10). Why Documentation Is Important. Retrieved May 21, 2016, from https://www.fastspot.com/publications/why-documentation-is-important/

iceskatingresources.org. (2016). The Learning Process. Retrieved May 30, 2016, from The Learning Process hosted by San Diego Figure Skating Communications a non-profit educational organization SDFSCEnews.Org: http://iceskatingresources.org/ProcessOfSystematicLearning.html

Judeh, M. (2008, December 18). Is half knowledge too dangerous? Retrieved May 30, 2016, from ResearchGate: https://www.researchgate.net/post/Is_half_knowledge_too_dangerous

Medicines and Healthcare Products Regulatory Agency, Government of United Kingdom. (2015). MHRA GMP Data Integrity Definitions and Guidance for Industry March 2015. London: Government of United Kingdom.

Mohanty, P. C. (2010). Handicrafts: The Visible Cultural Symbol of Ganjam District. Orissa Review , 42.

Oguamanam, C. (2009). Documentation and Digitization of Traditional Knowledge and Intangible Cultural Knowledge: Challenges and Prospects. Intangible Cultural Heritage and Intellectual Property: Cultural Diversity and Sustainable Development (Antwerp: Intersentia, 2009) , 357-383.

Parampra Project, Ministry of Culture. (2014). Brass and Bell metal Works. Retrieved December 18, 2014, from Traditional craftsmanship > Brass and Bell metal Works: http://www.paramparaproject.org/traditions_brass-metal.html 
Priya Ranjan Mahalik, D. R. (2010). Documenting Indigenous Traditional Knowledge in Odisha. Orissa Review , 99-103.

S. S. Panwalkar, W. I. (1977). A Survey of Scheduling Rules. Operations Research, Vol-25, Issue-1 , 45-61.

Simon Dalby, F. M. (June 1997). Reconceptualising local community: environment, identity and threat. AREA: Royal Geographical Society Journal, Volume 29, Issue 2 , 99-108.

Small Industries Service Institute, Ministry of Small Scale Industries, Government of India. (2005). Diagnostic study report of brass and bell metal cluster at Balakanti, Khurda. Cuttack: Small Industries Service Institute, Cuttack.

Staff Reporter, The Hindu. (2006, December 21). A kaleidoscope of crafts. Retrieved May 30, 2016, from The Hindu: http://www.thehindu.com/todays-paper/tp-national/tp-andhrapradesh/a-kaleidoscope-ofcrafts/article3036650.ece

TAB. (2016). Color-Coding and Labels/Benefits of Color Coding. Retrieved June 24, 2016, from http://www.tab.com/filing-equipment/color-coded-file-labels

Tango International. (2009). Sustainability of rural development projects. International Fund for Agricultural Development. Rome, Italy: The International Fund for Agricultural Development.

\section{Notes}

i (dictionary.com, 2016)

ii (Halvorsen, 2011)

iii (TAB, 2016)

iv (Blutner, Basic Colors, 2016)

v (Directorate of Handicraft and Cottage Industries, Government of Odisha, 2015)

vi (Simon Dalby, June 1997)

vii (Council of Handicrafts Development Corporation, 2014)

viii (Parampra Project, Ministry of Culture, 2014)

ix (Mohanty D. P., 2010)

${ }^{x}$ (foxycart!, 2016)

xi (Small Industries Service Institute, Ministry of Small Scale Industries, Government of India, 2005)

xii (Tango International, 2009)

xiii (Chatterjee, 2015, pp. 19-23)

xiv (Bhattacharya, 2011, pp. 10-13)

${ }^{\mathrm{xv}}$ (Craftmark: Hand Made in India, 2014)

xvi (Craft and Artisans, 2010)

xvii (Crafts Council of India, 2014)

xviii (Council of Handicrafts Development Corporations, Ministry of Textiles, Government of India)

xix (Mohanty P. C., 2010)

${ }^{x x}$ (S. S. Panwalkar, 1977, pp. 45-61)

xxi (Priya Ranjan Mahalik, 2010)

xxii (Oguamanam, 2009) 